\title{
Prevalence and Predictors of Rheumatic Heart Disease among School Children in Mansoura District, Egypt
}

\author{
${ }^{1}$ Sherif Arafa, ${ }^{2}$ Doaa Alemam, ${ }^{1}$ Nader El Shahat, ${ }^{1}$ Nermin Elghamrawy, ${ }^{2}$ Sherehan \\ Abdelsalam \\ ${ }^{1}$ Cardiovascular medicine, Faculty of Medicine, Mansoura University, Egypt. ${ }^{2}$ Community \\ Medicine Department, Faculty of Medicine, Mansoura University, Egypt
}

Submission Date: 04-04-2021Ｒevision Date: 08-05-2021_Acceptance Date: 09-05-2021

\begin{abstract}
Background: Rheumatic heart disease (RHD), a long-term complication of acute rheumatic fever (ARF), is still the main cause of paediatrics acquired heart disease, premature deaths and disabilities among indigenous Egyptian populations. It influences mostly children and young adults. Objective: This study aimed to estimate the prevalence of RHD detected by echocardiographic screening among school children (age 5-18) in Mansoura District at Dakahlia governorate, Egypt. Method: This descriptive cross-sectional study included 4847 school children recruited from the governmental urban \& rural schools considering the pattern of population distribution in rural and urban areas in Mansoura. A predesigned structured questionnaire was given to parents of children. All children were examined by echocardiographic examination to detect RHD. Results: The prevalence of RHD among studied group was $0.9 \%$. The most significant predictive factors for RHD were urban residence, overcrowding, positive surgical history of tonsillectomy and being on long acting penicillin. Conclusion: The utilization of echocardiographic screening for diagnosing RHD can prevent both its over- and under-diagnosis
\end{abstract}

Keywords: Rheumatic heart disease - school children- echocardiographic Doppler examination

Corresponding Author: Doaa Shokry Alemam Email: dr_doaashokry@ hotmail.com

dr_doaashokry@mans.edu.eg

\section{Introduction}

RHD is the commonest acquired cardiovascular disease worldwide. It results in congestive heart failure, stroke as well as dysrhythmia. Almost eliminated in highincome countries but it still exists in lowand middle-income countries. It is a major cause of heart failure among children and young adults leading to disabilities and premature deaths. ${ }^{1}$

The prevalence of RHD varied greatly between countries and even between different ethnic groups within the same country during the last 10 years of the last century in developing countries, the large number of cardiac surgical procedures is due to RHD which constitute a significant burden on the individual, the family and the community at large and a drain of the economy. ${ }^{2}$

Currently, the yearly incidence varied from $<0.5 / 100000$ in high income countries to $>$ $100 / 100000$ in poor countries. ${ }^{3}$ The incidence of acute rheumatic fever and RHD is elevated among children aged 5 - 14 years. In some cases, the first episode could happen in those aged two to three years. ${ }^{4}$ RHD disproportionately influences children living in poor, unhygienic and 
overcrowded environments. Factors including deficient resources for providing quality health-care, insufficient knowledge of health-care providers and poor awareness about RHD are linked to its occurrence. ${ }^{5}$

Attempts to tackle the burden of RHD, have not been successfully implemented in lowand middle-income countries due to structural weaknesses of the health system. Currently, RHD is still the leading aetiology of heart-related mortalities in poor nations. ${ }^{1}$ Early detection of subclinical RHD is essential in order to detect cases at a time when penicillin has the ability to prevent progression to valvular disease in early adult life. $^{6}$

There is increased utilization of portable echocardiography for screening of RHD. Minimal echocardiographic characteristics of RHD have recently been elucidated. ${ }^{7}$

Echocardiography is known to be more sensitive than auscultation for the detection of pathologic valve disease, and the recent availability of high-quality portable ultrasound equipment makes it possible to screen large numbers of children at schools in developing nations. ${ }^{8}$

Having updated estimate up to date estimation of the prevalence of RHD among school children is highly desirable to facilitate health care planning .The current study aims to determine the prevalence of RHD detected by echocardiography among school children (age 5-18) in Mansoura District at Dakahlia governorate in Egypt and to find out the determinants of RHD among them.

\section{Method}

A descriptive cross-sectional study was performed on school children aged 5-18 (primary, preparatory and Secondary schools) in Mansoura District at Dakahlia governorate in Egypt during the period from September 2019 to December 2019.
Exclusion criteria included congenital heart disease, other autoimmune disease affecting valves as SLE or juvenile rheumatoid arthritis, end-stage LCF or RF which was uncommon and malignancy mainly blood diseases.

The calculated sample size was 4227 participants at 5\% level of significance and 95\% power of the study, using $G^{*}$ Power 3 sample size calculator.

Prevalence of RHD in Egyptian school children $(2.2 \%)$ (EL-Aroussy, et al, 2013). It was increased to 5000 participants for compensation for incomplete data and to boost the power of the study.153 child refused to do echocardiography. So the total number of the studied group was 4847 with response rate $96.9 \%$.

The study was carried out in the governmental urban \& rural schools that were selected randomly. Considering the pattern of population distribution in rural and urban areas in Mansoura, one third of the sample size was obtained from the urban schools. The other two thirds was obtained from the rural ones. Then cluster sampling of classes was done to select 5000 child.

A predesigned structured questionnaire was given to parents of children. It included socio-demographic characteristics such as age, sex, residence, father and mother's job, income and crowding index, medical history of long acting penicillin and surgical history of tonsillectomy.

Calculating crowding index: According to our quantitative analysis of crowding data from Central Agency for Public Mobilization and Statistics (CAPMAS) in 2006, and based on the international definitions and measurements for crowding, the average crowding index in Egypt was $<1.5$ subjects/room; medium crowding was 1.5 - 1.7 subjects/room; and overcrowding was $>1.8$ subjects/room.

General, local examination and Complete Transthoracic ECHO were done. 
Table (1): Socio-demographic characteristics, Crowding index, surgical and medical history among studied students $(\mathrm{N}=4847)$.

\begin{tabular}{|c|c|}
\hline $\begin{array}{l}\text { Socio-demographic } \\
\text { characteristics }\end{array}$ & $\begin{array}{l}\text { The studied } \\
\text { group } \\
(\mathrm{n}=4847)\end{array}$ \\
\hline $\begin{array}{l}\text { Age (years) } \\
\text { Mean } \pm \text { SD } \\
\text { Min-Max }\end{array}$ & $\begin{array}{c}9.51 \pm 2.9 \\
5-15\end{array}$ \\
\hline $\begin{array}{l}\text { Sex } \\
\text { Male } \\
\text { Female }\end{array}$ & $\begin{array}{l}2266(46.8 \%) \\
2581(53.2 \%) \\
\end{array}$ \\
\hline $\begin{array}{l}\text { Residence } \\
\text { Urban } \\
\text { Rural } \\
\end{array}$ & $\begin{array}{l}1599(33.0 \%) \\
3248(67.0 \%)\end{array}$ \\
\hline $\begin{array}{l}\text { Education } \\
\text { Nursery } \\
\text { Primary } \\
\text { Preparatory } \\
\text { Secondary }\end{array}$ & $\begin{array}{r}628(13.0 \%) \\
3254(67.1 \%) \\
923(19.0 \%) \\
42(0.9 \%)\end{array}$ \\
\hline $\begin{array}{l}\text { Father job** }(\mathbf{n}=\mathbf{4 8 2 4}) \\
\text { Worker } \\
\text { Non worker }\end{array}$ & $\begin{array}{r}4739(98.2 \%) \\
85(1.8 \%)\end{array}$ \\
\hline $\begin{array}{l}\text { Mother job** }(\mathbf{n}=\mathbf{4 8 4 4}) \\
\text { Worker } \\
\text { Housewife }\end{array}$ & $\begin{array}{r}669(13.8 \%) \\
4175(86.2 \%) \\
\end{array}$ \\
\hline $\begin{array}{l}\text { Income } \\
\text { Insufficient } \\
\text { Sufficient }\end{array}$ & $\begin{array}{r}4002(82.6 \%) \\
845(17.4 \%)\end{array}$ \\
\hline $\begin{array}{l}\text { Crowding } \\
\text { index(subjects/room) } \\
\text { Mean } \pm \text { SD } \\
\text { Min-Max }\end{array}$ & $\begin{array}{r}1.46 \pm 0.39 \\
0.5-6\end{array}$ \\
\hline $\begin{array}{l}\text { Acceptable } \\
\text { Medium crowding } \\
\text { Over crowding }\end{array}$ & $\begin{array}{r}844(17.4 \%) \\
3993(82.4 \%) \\
10(0.2 \%)\end{array}$ \\
\hline $\begin{array}{l}\text { Tonsillectomy } \\
\text { Positive } \\
\text { Negative }\end{array}$ & $\begin{array}{r}499(10.3 \%) \\
4348(89.7 \%)\end{array}$ \\
\hline $\begin{array}{l}\text { Long acing penicillin } \\
\text { Positive } \\
\text { Negative }\end{array}$ & $\begin{array}{r}706(14.6 \%) \\
4141(85.4 \%)\end{array}$ \\
\hline $\begin{array}{l}\text { ECHO findings } \\
\text { Normal } \\
\text { RHD }\end{array}$ & $\begin{array}{r}4803(99.1 \%) \\
44(0.9 \%)\end{array}$ \\
\hline
\end{tabular}

The results were obtained using Vivid E portable Echo and it was done under supervision of consultant echocardiographer. $2 D$ mode: To assess morphology of mitral valve apparatus \&



Figure (1): Prevalence of RHD by echocardiography among school children Aortic valve mainly as regards thickening \& Mobility of leaflets /Tips, chordae, commissures, papillary muscles \& valve opening/area by planimetry.

M-mode: to assess LA/LV dimensions, AV cusp opening and MVL excursion.

Doppler study: Pulsed wave Doppler of MV /AV flow to assess low velocity flow or Continuous Doppler of MV /AV to assess mean/peak Gradient, MVA by PHT. Heart underwent examination in parasternal long axis, short axis and apical four chamber views.

Criteria utilized for defining subclinical RHD by Echocardiography WHO, 2012:

The combined criteria:

Doppler criteria: A regurgitant jet $>1 \mathrm{~cm}$ in length, a regurgitant jet in at least two planes, a mosaic color jet with a peak velocity $>2.5 \mathrm{~m} / \mathrm{s}$, the jet persists throughout systole and diastole B) Morphological signs:

Leaflet restriction, Sub valvular thickening, Valvular thickening, Beading $\backslash$ nodularity of leaflet tips.

\section{Statistical Analysis}

This was done using Statistical Package for Social Sciences (Standard version 24). Qualitative data were represented as number and \%. Chi-square ( $\chi 2)$ test compared between the groups. Quantitative data were represented as mean (SD) after normality testing by Kolmogorov-Smirnov test. Independent sample $t$-test was utilized 
Table (3): Socio demographic characteristics, Crowding index, surgical and medical history among students with RHD versus normal students

\begin{tabular}{|c|c|c|c|c|}
\hline $\begin{array}{l}\text { Socio-demographic } \\
\text { characteristics }\end{array}$ & $\begin{array}{c}\text { RHD } \\
(n=44)\end{array}$ & $\begin{array}{c}\text { Normal } \\
(n=4803)\end{array}$ & $\begin{array}{c}\text { Test of } \\
\text { significance } \\
\text { (p value) }\end{array}$ & $\operatorname{COR}(95 \% \mathrm{CI})$ \\
\hline $\begin{array}{l}\text { Age (years) } \\
\text { Mean } \pm \text { SD }\end{array}$ & $9.46 \pm 2.95$ & $9.84 \pm 2.52$ & $0.85(0.396)$ & - \\
\hline $\begin{array}{l}\text { Sex } \\
\text { Male (r) } \\
\text { Female }\end{array}$ & $\begin{array}{r}18(0.8) \\
26(1)\end{array}$ & $\begin{array}{r}2246(99.2) \\
2557(99)\end{array}$ & $0.60(0.438)$ & $1.3(0.7-2.3)$ \\
\hline $\begin{array}{l}\text { Residence } \\
\text { Urban } \\
\text { Rural (r) } \\
\end{array}$ & $\begin{array}{l}24(1.5) \\
20(0.6)\end{array}$ & $\begin{array}{l}1575(98.5) \\
3228(99.4)\end{array}$ & $9.33(0.002 *)$ & $\begin{array}{c}2.5(1.3-4.5) \\
1\end{array}$ \\
\hline $\begin{array}{l}\text { Education } \\
\text { Nursery (r) } \\
\text { Primary } \\
\text { Preparatory } \\
\text { Secondary }\end{array}$ & $\begin{array}{r}3(0.5) \\
36(1.1) \\
5(0.5) \\
0(0)\end{array}$ & $\begin{array}{r}625(99.5) \\
3218(98.9) \\
918(99.5) \\
42(100)\end{array}$ & $\begin{array}{l}- \\
2.09(0.15) \\
0.03(0.86) \\
\text { Undefined }\end{array}$ & $\begin{array}{c}1 \\
2.3(0.7-7.6) \\
1.1(0.3-4.7) \\
\text { Undefined }\end{array}$ \\
\hline $\begin{array}{l}\text { Father job } \\
\text { Worker (r) } \\
\text { Non worker } \\
\end{array}$ & $\begin{array}{r}41(0.9) \\
1(1.2) \\
\end{array}$ & $\begin{array}{r}4698(99.1) \\
84(98.8) \\
\end{array}$ & FET $(0.528)$ & $1.4(0.2-10)$ \\
\hline $\begin{array}{l}\text { Mother job } \\
\text { Worker } \\
\text { Housewife (r) }\end{array}$ & $\begin{array}{r}9(1.3) \\
35(0.8)\end{array}$ & $\begin{array}{r}660(98.7) \\
4140(99.2)\end{array}$ & $1.65(0.199)$ & $1.6(0.8-3.4)$ \\
\hline $\begin{array}{l}\text { Income } \\
\text { Insufficient } \\
\text { Sufficient (r) }\end{array}$ & $\begin{array}{l}39(1) \\
5(0.6)\end{array}$ & $\begin{array}{r}3963(99) \\
840(99.4)\end{array}$ & $1.14(0.286)$ & $1.6(0.6-4.2)$ \\
\hline $\begin{array}{l}\text { Crowding index } \\
\text { (subjects/room) } \\
\text { Acceptable (r) } \\
\text { Medium } \\
\text { Over crowding }\end{array}$ & $\begin{array}{r}8(0.9) \\
32(0.8) \\
4(40)\end{array}$ & $\begin{array}{r}836(99.1) \\
3961(99.2) \\
6(60) \\
\end{array}$ & $\begin{array}{c}- \\
0.2(0.67) \\
108\left(\leq 0.001^{* *}\right) \\
\end{array}$ & $\begin{array}{c}1 \\
0.8(0.4-1.8) \\
69(16-295) \\
\end{array}$ \\
\hline $\begin{array}{l}\text { Tonsillectomy } \\
\text { Positive } \\
\text { Negative (r) }\end{array}$ & $\begin{array}{l}16(3.2) \\
28(0.6)\end{array}$ & $\begin{array}{r}483(96.8) \\
4320(99.4)\end{array}$ & $32.7\left(\leq 0.001^{* *}\right)$ & $5.1(2.7-9.5)$ \\
\hline $\begin{array}{l}\text { Long acing penicillin } \\
\text { Positive } \\
\text { Negative (r) }\end{array}$ & $\begin{array}{l}25(3.5) \\
19(0.5)\end{array}$ & $\begin{array}{r}681(96.5) \\
4122(99.5)\end{array}$ & $63.7(\leq 0.001 * *)$ & $7.9(4.4-14.5)$ \\
\hline \multicolumn{5}{|c|}{$\begin{array}{l}\text { *significant } p \leq 0.05, * * \text { highly significant } \leq 0.001, \text { COR: crude odds ratio, CI: confidence interval } \\
\text { Table (2): Echocardiographic findings of rheumatic patients }(\mathbf{n = 4 4 )}\end{array}$} \\
\hline \multicolumn{3}{|c|}{ Echocardiographic findings } & \multicolumn{2}{|l|}{$\begin{array}{c}\text { RHD } \\
(\mathrm{n}=44)\end{array}$} \\
\hline $\begin{array}{l}\text { Mitral regurgitation } \\
\text { Mild } \\
\text { Moderate } \\
\text { Trivial }\end{array}$ & & & & $\begin{array}{r}39(\mathbf{8 8 . 6 \% )}) \\
35(89.7 \%) \\
1(2.6 \%) \\
3(7.7 \%)\end{array}$ \\
\hline $\begin{array}{l}\text { Aortic regurgitation } \\
\text { Mild }\end{array}$ & & & & $\begin{array}{r}\mathbf{5}(\mathbf{1 1 . 4 \%}) \\
5(100 \%)\end{array}$ \\
\hline
\end{tabular}


to compare between groups. Binary stepwise logistic regression analysis predicted the independent variables. Significant predictors in univariate analysis were entered into regression model. Odds ratios and their $95 \% \mathrm{CI}$ underwent calculation. " $p$ value $\leq 0.05$ "was statistically significant result.

\section{Ethical consideration}

The study protocol obtained its approval by IRB (Institutional Research Board) of Faculty of Medicine (No. MS/17.05.131). Written consent was taken from parents of entire participants. Confidentiality was maintained throughout the study.

\section{Results}

The study was conducted on 4847 school children. The mean age was $9.51 \pm 2.9$ years with almost equal distribution as regards the sex. Approximately $67 \%$ of children were rural. Most of them (67\%) were in primary grades. Most of their fathers $(98.2 \%)$ were working whereas only $13.8 \%$ of their mothers were working. Nearly $82.6 \%$ of their parents had insufficient income. The mean crowding index was $1.46 \pm 0.39$ with nearly $82.4 \%$ of their houses were considered as medium crowding. Nearly $10 \%$ of students reported that they had surgical history of tonsillectomy and $14.6 \%$ were on long-acting penicillin. The prevalence of RHD among studied group was $0.9 \%$ as shown in table (1) and figure (1).

Valvular involvement in RHD children was predominately mitral regurgitation $(88.6 \%)$, while aortic regurgitation represented only $(11.4 \%)$ as shown in table (2).

On comparing both RHD versus normal groups regarding their socio demographic characters in (table 3), residence and crowding index were found to have statistically significant association with
Table (4): Multivariate Logistic regression analysis of independent predictors of RHD

\begin{tabular}{|c|c|c|c|}
\hline Predictor & $\boldsymbol{\beta}$ & $\begin{array}{c}P \text { - } \\
\text { value }\end{array}$ & $\begin{array}{c}\text { AOR } \\
(95 \% \mathrm{CI})\end{array}$ \\
\hline $\begin{array}{l}\text { Residence } \\
\text { Urban } \\
\text { Rural (r) }\end{array}$ & 0.967 & 0.002 & $2.6(1.4-4.9)$ \\
\hline $\begin{array}{l}\text { Crowding } \\
\text { index } \\
\text { Over crowded }\end{array}$ & 4.112 & $\leq 0.001$ & $61(11-313)$ \\
\hline $\begin{array}{l}\text { Tonsillectomy } \\
\text { Positive } \\
\text { Negative (r) }\end{array}$ & 0.907 & 0.009 & $2.5(1.2-4.9)$ \\
\hline $\begin{array}{l}\text { Long acing } \\
\text { penicillin } \\
\text { Positive } \\
\text { Negative (r) }\end{array}$ & 1.919 & $\leq 0.001$ & $6.8(3.6-13)$ \\
\hline $\begin{array}{l}\text { Constant }=-5.9 \\
\text { Model } \chi^{2}=82.4 \\
\text { Predicted \% }=9\end{array}$ & $\begin{array}{l}\mathrm{p} \leq 0.0 \\
1 \%\end{array}$ & & \\
\hline
\end{tabular}

RHD among studied group. RHD was 2.5 more times among urban and 69 more times in overcrowded houses. Also, RHD was 5.1 and 7.9 more times among those with surgical history of tonsillectomy and those with medical history of long-acting penicillin; respectively. Among all significant variables in univariate analysis, urban residence, overcrowding, positive surgical history of tonsillectomy and being on long-acting penicillin were found to be independent risk factors for $\mathrm{CHD}$, with estimated odds ratio of $(2.6,61,2.5$ and 6.8., respectively) as shown in logistic regression analysis (table 4)

\section{Discussion}

In Egypt, epidemiological surveys showed that RHD was the commonest serious heart disease as it was estimated to exist in approximately $0.8-2 \%$ in spite of long acting penicillin administration. ${ }^{9}$ The current study reported that echocardiographic prevalence of RHD was $0.9 \%$ (9/1000 students) which is near to the prevalence that was reported by WHO control program in 2004 (9.8 per thousand 
school children 6-12 years old $\mathrm{WHO}^{10}$ and by Baroux et al. ${ }^{11}$ in New Caledonia in west pacific where the prevalence was $f 8.9$ cases per 1000 (95\% CI) (7.3-10.6). A recent study by Musuku et al. ${ }^{12}$ in Zambia stated that RHD prevalence was 11.8 per 1000 .

This current prevalence result is higher than that found among school children by Deraz et al. ${ }^{13}$ in Dakahlia in Egypt and Nair et $a l^{14}$ in south India with estimated prevalence rates were $1 / 1000$ and 5.83/1000; respectively. This discrepancy may be due to application of different approach as echocardiography was applied only on those who had clinical positive finding in those previous studies

On the other hand, earlier studies utilizing echocardiographic screening reported greater prevalence of RHD in school-age children, including studies by Marijon et al. ${ }^{15}$ in Cambodia (30.4 per 1000), Carapetis et al. ${ }^{16}$ in Tonga (33.2 per 1000), Sadiq et al. ${ }^{17}$ in Pakistan (21.9/1000) and Saxena et al. ${ }^{18}$ (14/1000).

Systematic screening using echocardiography revealed greater prevalence of RHD in comparison with clinical screening. Different echocardiographic criteria for RHD diagnosis may result in difference of RHD prevalence and essentially make epidemiological comparisons invalid. So, to close this gap, World Heart Federation (WHF) published the first internationally endorsed evidence-based criteria for echocardiographic diagnosis of RHD in 2012. ${ }^{6}$ These guidelines removed clinical examination from diagnosis and divided RHD into definite and borderline as well as providing subcategories within each for different combinations of diseases (isolated valvular regurgitation, isolated morphological alteration, etc.). But it allowed quick detection of RHD in patients with no history of ARF.
Valvular involvement in RHD children in this current study was predominately mitral regurge $(88.6 \%)$ and this is consistent with other local and worldwide studies $\mathrm{El}$ Aroussy et al. ${ }^{19}$, Elamrousy et al. ${ }^{20}$ and Ghamrawy et al. ${ }^{21}$ in Egypt and by Lubega et al. ${ }^{22}$ in Uganda and Badiani et al. ${ }^{23}$

By using multivariate Logistic regression analysis, the current study reported that RHD was 2.6 more times among urban children. These results go with finding of Riaz et al. ${ }^{24}$ and Ghamrawy et al. ${ }^{21}$ Many Egyptian villages have shown rapid urbanization, resulting in congested socioeconomically depressed localities. ${ }^{21}$ This explains why urban residency in our study linked to RHD. However RHD was more common among cases from rural locations in studies done by Carapetis et al. ${ }^{25}$ and Baker et al. ${ }^{26}$ The current study also showed that RHD 69 more times in overcrowded houses. This also runs with previous reports from around the world by Watkins et al. ${ }^{27}$ and Sharma et al. ${ }^{28}$

RHD was 2.5and 6.8 more times among those with surgical history of tonsillectomy and those with medical history of longacting penicillin; respectively and this was in accordance with the results of Ghamrawy et al (2020). Though the majority of children having repeated attacks of tonsillitis were instructed to perform tonsillectomy prior to the study, a considerable number ultimately developed ARF in its different presentations. In Egypt, family makes a decision to perform tonsillectomy to prevent recurrent respiratory infections or frequent attacks of tonsillitis, although ARF and its complications may have been already developed. Families that had their children tonsillectomized do not look for therapy for succeeding attacks of pharyngitis since they believe that tonsillectomy will eradicate infection and prevent ARF and RHD. This reveals a minimal awareness regarding the 
disease as well as insufficient expertise of health-care providers. There is significant evidence that tonsillectomy does not change the susceptibility to streptococcal infection or its outcomes. Once that infection is established, the existence or nonexistence of tonsils does not change the clinical course. Furthermore, it seems that streptococcal infection is less readily identified in tonsillectomized subjects and, thus, is more likely to escape therapy appropriate for ARF prevention Powell et $a .^{29}$

\section{Conclusions}

The echocardiographic prevalence of RHD among studied group was $0.9 \%$. The most significant predictive factors for RHD were urban residence, overcrowding, positive surgical history of tonsillectomy and being on long-acting penicillin.

Recommendation: Sustained outreach RHD screening campaigns as well as school-based clinics employing echocardiography must be carried out in marginalized communities for early RHD determination. Formulating national guidelines, applying a well-organized national strategy, upgrading national registry system through applying REDCap (Research Electronic Data Capture), capacity building, better access to echocardiography, promoting research for new streptococcal vaccine candidates, and adopting proper investigations must be ensured.

Study limitations: our study did not focus on finding new factors which might have an enhanced risk, rather looked for the identified risk factors and how these operate in Egyptian population. Data regarding housing conditions were deficient and were dependent upon interview with participants and have not been ascertained through household visits because of time and resource constraints.

Conflicts of Interests: None

Funding: None.

Availability of data and material: The study's data are available from the corresponding author on reasonable request

\section{References:}

1. Condemi F, Rossi G, Lupiz M, Pagano A, Zamatto F, Marini S, et al. Screening of asymptomatic rheumatic heart disease among refugee/migrant children and youths in Italy. Pediatric Rheumatology. 2019;17(1).

2. Beaton A, Aliku T, Dewyer A, Jacobs M, Jiang J, Longenecker CT, et al. Latent Rheumatic Heart Disease. Circulation. 2017;136(23):2233-44.

3. Gewitz MH, Baltimore RS, Tani LY, Sable CA, Shulman ST, Carapetis J, et al. Revision of the Jones Criteria for the Diagnosis of Acute Rheumatic Fever in the Era of Doppler Echocardiography. Circulation. 2015;131(20):1806-18.

4. Parnaby MG, Carapetis JR. Rheumatic fever in Indigenous Australian children. Journal of Paediatrics and Child Health. 2010;46(9):52733.

5. Mirabel M, Fauchier T, Bacquelin R, Tafflet M, Germain A, Robillard C, et al. Echocardiography screening to detect rheumatic heart disease. International Journal of Cardiology. 2015;188:89-95.

6. Reményi B, Wilson N, Steer A, Ferreira B, Kado J, Kumar K, et al. World Heart Federation criteria for echocardiographic diagnosis of rheumatic heart disease - an evidence-based guideline. Nature Reviews Cardiology. 2012;9(5):297-309.

7. Marijon E, Mirabel M, Celermajer DS, Jouven X. Rheumatic heart disease. The Lancet. 2012;379(9819):953-64.

8. Cilliers AM. Rheumatic fever and its management. BMJ. 2006;333(7579):1153-6.

9. Kotit S, Said K, ElFaramawy A, Mahmoud H, Phillips DIW, Yacoub MH. Prevalence and prognostic value of echocardiographic screening for rheumatic heart disease. Open Heart. 2017;4(2):e000702.
No. 1

January

2022 
10.WHO. Rheumatic fever and rheumatic heart disease: report of a WHO Expert Consultation, Geneva, 29 October-1 November, 2001. World Health Organization. 2004;923.

11.Baroux N, Rouchon B, Huon B, Germain A, Meunier J-M, D'Ortenzio E. High prevalence of rheumatic heart disease in schoolchildren detected by echocardiography screening in New Caledonia. Journal of Paediatrics and Child Health. 2013;49(2):109-14.

12.Musuku J, Engel ME, Musonda P, Lungu JC, Machila E, Schwaninger S, et al. Prevalence of rheumatic heart disease in Zambian school children. BMC Cardiovascular Disorders. 2018;18(1).

13.Deraz SE, El-Zayat RS, Badawy AM. Prevalence of rheumatic heart disease in school children aged 6-15 years. Menoufia Medical Journal. 2020;33(1):162.

14.Nair B, Viswanathan S, Koshy AG, Gupta PN, Nair N, Thakkar A. Rheumatic Heart Disease in Kerala: A Vanishing Entity? An Echo Doppler Study in 5-15-Years-Old School Children. International Journal of Rheumatology. 2015;2015:1-6.

15.Marijon E, Ou P, Celermajer DS, Ferreira B, Mocumbi AO, Jani D, et al. Prevalence of Rheumatic Heart Disease Detected by Echocardiographic Screening. New England Journal of Medicine. 2007;357(5):470-6.

16.Carapetis JR, Hardy M, Fakakovikaetau T, Taib R, Wilkinson L, Penny DJ, et al. Evaluation of a screening protocol using auscultation and portable echocardiography to detect asymptomatic rheumatic heart disease in Tongan schoolchildren. Nature Clinical Practice Cardiovascular Medicine. 2008;5(7):411-7.

17.Sadiq M, Islam K, Abid R, Latif F, Rehman AU, Waheed A, et al. Prevalence of rheumatic heart disease in school children of urban Lahore. Heart. 2008;95(5):353-7.

18. Saxena A, Ramakrishnan S, Kant S, Roy A. 42 Echocardiographic screening for rheumatic heart disease among asymptomatic adults: study from a region with high prevalence of echocardiographic rhd in asymptomatic school children. Poster presentations; 2018/02: BMJ Publishing Group Ltd and British Cardiovascular Society; 2018.
19.El-Aroussy W, El-Hagracy N, Fawzy H, Zaher S, Taha N, Moustafa S. Prevalence of rheumatic valvular heart disease among Egyptian school children: an echocardiographic screening. The Medical Journal of Cairo University. 2013;81(2).

20.Elamrousy DM, Al-Asy H, Mawlana W. Acute Rheumatic Fever In Egyptian Children: A 30- YearExperience in a Tertiary Hospital. Journal of Pediatric Sciences. 2014;6(0).

21. Ghamrawy A, Ibrahim NN, Abd El-Wahab EW. How accurate is the diagnosis of rheumatic fever in Egypt? Data from the national rheumatic heart disease prevention and control program (2006-2018). PLOS Neglected Tropical Diseases. 2020;14(8):e0008558.

22.Lubega S, Aliku T, Lwabi P. Echocardiographic pattern and severity of valve dysfunction in children with rheumatic heart disease seen at Uganda Heart Institute, Mulago hospital. African Health Sciences. 2014;14(3):617.

23. Badiani S, van Zalen J, Saheecha S, Hart L, Topham A, Patel N, et al. Clinical events and echocardiographic lesion progression rate in subjects with mild or moderate aortic regurgitation. Echo Research and Practice. 2017;4(3):37-44.

24.Riaz BK, Selim S, Karim MN, Chowdhury KN, Chowdhury SH, Rahman MR. Risk Factors of Rheumatic Heart Disease in Bangladesh: A Case-Control Study. Journal of Health, Population and Nutrition. 2013;31(1).

25.Carapetis JR, Beaton A, Cunningham MW, Guilherme L, Karthikeyan G, Mayosi BM, et al. Acute rheumatic fever and rheumatic heart disease. Nature Reviews Disease Primers. 2016;2(1).

26.Baker MG, Gurney J, Oliver J, Moreland NJ, Williamson DA, Pierse N, et al. Risk Factors for Acute Rheumatic Fever: Literature Review and Protocol for a Case-Control Study in New Zealand. International Journal of Environmental Research and Public Health. 2019;16(22):4515.

27. Watkins DA, Johnson CO, Colquhoun SM, Karthikeyan G, Beaton A, Bukhman G, et al. Global, Regional, and National Burden of Rheumatic Heart Disease, 1990-2015. New 
England Journal of Medicine. 2017;377(8):71322.

28. Sharma N, Toor D. Impact of SocioEconomic Factors on Increased Risk and Progression of Rheumatic Heart Disease in Developing Nations. Current Infectious Disease Reports. 2019;21(6).
29.Powell J, O’Hara J, Carrie S, Wilson JA. Is tonsillectomy recommended in adults with recurrent tonsillitis? BMJ. 2017:j1450. 